\title{
Vigabatrin and depression
}

\author{
H A Ring, R Crellin, S Kirker, E H Reynolds
}

\begin{abstract}
Ten patients who developed a major depressive episode in association with vigabatrin treatment for intractable epilepsy are reported. The depression usually occurred early in the course of treatment, but when delayed followed a recent increase in dose. Depressive symptoms occurred at doses varying between $1.5 \mathrm{~g}$ and $4 \mathrm{~g}$ a day, often but not always when patients were experiencing a decrease in their seizure frequency. Most patients had a history of affective disturbance, sometimes in association with other GABAergic drugs. The observations support a possible role for GABAergic mechanisms in the biology of mood disorders.
\end{abstract}

$(\mathcal{F}$ Neurol Neurosurg Psychiatry 1993;56:925-928)

The side effects of vigabatrin are in many respects similar to those reported for other standard antiepileptic drugs, the most common being drowsiness, dizziness, and irritability. ${ }^{1}$ In a clinical trial we noted an increased incidence of depression in addition to the usually reported adverse effects. Four of the 33 patients entering this study were subsequently withdrawn with this complication. ${ }^{2}$ Furthermore, within the context of this trial mood rating scales showed an overall though non-significant deterioration in mood in the patients, despite the fact that two thirds of them showed at least a $50 \%$ improvement in seizure control (K A Birbeck et al, 18th epilepsy international congress, New Delhi, 1989). Since completing our trial we have observed further patients with severe depression associated with vigabatrin during routine clinical practice. In this report we discuss the depression related to vigabatrin treatment in more detail in a series of 10 patients comprising the four patients briefly mentioned in our clinical trial ${ }^{2}$ and six subsequent patients.

\section{Case reports}

The clinical characteristics of 10 patients who became significantly depressed taking vigabatrin are listed in tables 1 and 2. Five of the patients were being treated with carbamazepine alone before vigabatrin was added, four were taking one other anticonvulsant (sodium valproate, phenytoin, clobazam, or phenobarbitone) in addition to carbamazepine, and one was taking phenytoin and sodium valproate.

Two illustrative case histories are presented in more detail.

\section{Case 7}

This 25 year old male student had experienced complex partial and secondarily generalised seizures of unknown aetiology from the age of 5 years. Electroencephalography showed left temporal epileptiform abnormali-
Department of

Neurology, Maudsley

and Kings College

Hospitals, London

H A Ring

R Crellin

$S$ Kirker

E H Reynolds

Correspondence to:

Dr E H Reynolds,

Department of Neurology,

Kings College Hospital,

London SE5 9RS.

Received 21 February 1992 and in revised form

30 September 1992

Accepted 9 October 1992

Table 1 Clinical characteristics of patients studied

\begin{tabular}{|c|c|c|c|c|c|c|c|}
\hline \multirow{3}{*}{$\begin{array}{l}\text { Case } \\
\text { no }\end{array}$} & \multirow{3}{*}{$\begin{array}{l}\text { Age } \\
\text { (years) }\end{array}$} & \multirow[b]{3}{*}{ Sex } & \multicolumn{2}{|c|}{ Seizure } & \multicolumn{2}{|l|}{ History } & \multirow[b]{3}{*}{$E E G$} \\
\hline & & & & No/month before & & & \\
\hline & & & Type & vigabatrin & Medical & Psychiatric & \\
\hline 1 & 24 & $\mathrm{~F}$ & CPS & 17 & - & - & Bilateral, generalised \\
\hline 2 & 38 & $\mathrm{~F}$ & PGS & 2 & - & $\begin{array}{l}\text { Depression aged } 27 \\
\text { and } 32 \text { with } \\
\text { phenobarbitone }\end{array}$ & 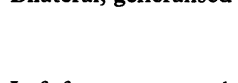 \\
\hline 3 & 41 & $\mathrm{M}$ & CPS & 4 & - & & Left fronto temporal \\
\hline 4 & 26 & $\mathrm{~F}$ & CPS & 14 & - & $\begin{array}{l}\text { Depression aged } 19 \\
\text { with primidone }\end{array}$ & Left temporal \\
\hline 5 & 24 & F & CPS & 5 & $\begin{array}{l}\text { Congenital right } \\
\text { hemiplegia }\end{array}$ & $\begin{array}{l}\text { Aggressive in childhood } \\
\text { with phenobarbitone }\end{array}$ & Left frontal \\
\hline 6 & 29 & F & CPS & 20 & $\begin{array}{l}\text { Meningitis, lead } \\
\text { encephalopathy }\end{array}$ & Depression aged 24 & - \\
\hline 7 & 25 & $\mathrm{M}$ & CPS & 10 & - & $\bar{\sigma}$ & Left temporal \\
\hline 8 & 54 & $\mathrm{~F}$ & CPS & 5 & - & $\begin{array}{l}\text { Four depressive } \\
\text { episodes aged 46-51 }\end{array}$ & Right temporal \\
\hline 9 & 42 & F & CPS & 16 & - & $\begin{array}{l}\text { Depression aged } 19 \\
\text { with }\end{array}$ & Bilateral \\
\hline 10 & 29 & $\mathbf{F}$ & CPS & 20 & - & Depression aged 21 & Left frontal temporal \\
\hline
\end{tabular}

CPS = complex partial seizures with or without secondary generalisation. $\mathrm{PGS}=$ primary generalised seizures . 
ties. Brain computed tomography showed a suprasellar mass, probably a hypothalamic hamartoma. Before vigabatrin was introduced he had been treated with all the standard antiepileptic drugs, singly or in various combinations. He continued to experience both partial and generalised seizures approximately 10 times monthly, despite treatment with carbamazepine alone with optimum blood concentrations. Vigabatrin was introduced at a dose of $1.0 \mathrm{~g}$ daily, and a week later the dose was increased to $2 \cdot 0 \mathrm{~g}$ daily. One week later he rapidly became depressed without any change in seizure frequency. He reported feeling depressed and thinking about suicide for the first time in his life. He became anxious about going out and stopped attending college. His appetite diminished and his sleep was disturbed by early morning waking. At interview he was both tearful and irritable with reduced self esteem.

The patient remained depressed for one week taking vigabatrin at a dose of $2.0 \mathrm{~g}$ a day and also during the following week, when vigabatrin was withdrawn. His mood returned to normal two weeks later. $\mathrm{He}$ did not know why he had become depressed. There had been no significant life events at this time. He had no history or family history of psychiatric disturbance.

\section{Case 9}

This 42 year old woman had experienced complex partial seizures of unknown origin since the age of 8 . Electroencephalography showed bilateral temporal lobe sharp waves with a possible right sided emphasis. Brain computed tomography showed a slightly smaller right hemicranium, although the temporal horns were symmetrical. There was no history of perinatal injury.

Before treatment with vigabatrin she had received all the major antiepileptic drugs. After vigabatrin was added to optimal blood concentrations of carbamazepine the initial seizure frequency of four fits a week fell to two and the severity and duration of the seizures also improved. After the temporary occurrence of drowsiness, dizziness, and blurred vision she continued to take vigabatrin $3 \mathrm{~g}$ daily for the next three years. Then vigabatrin was increased to $3.5 \mathrm{~g}$ a day in a further attempt to improve seizure control.

Table 2 Treatment characteristics of depression associated with vigabatrin in patients studied

\begin{tabular}{ccclll}
\hline Case no & $\begin{array}{l}\text { Vigabatrin } \\
\text { duration before } \\
\text { depression } \\
\text { (weeks) }\end{array}$ & $\begin{array}{l}\text { Dose at } \\
\text { onset of } \\
\text { depression } \\
\text { (g/day) }\end{array}$ & $\begin{array}{l}\text { Duration of } \\
\text { depression with } \\
\text { vigabatrin } \\
\text { (weeks) }\end{array}$ & $\begin{array}{l}\text { Duration of } \\
\text { depression after } \\
\text { stopping } \\
\text { vigabatrin (weeks) }\end{array}$ & $\begin{array}{l}\text { Reduction } \\
\text { in seizure } \\
\text { frequency at } \\
\text { maximum dose (\%)* }\end{array}$ \\
\hline 1 & 8 & $3 \cdot 0$ & 58 & 6 & $>50$ \\
2 & 8 & $2 \cdot 5$ & 40 & 3 & $>75$ \\
3 & 4 & $3 \cdot 0$ & 3 & 2 & $>75$ \\
4 & 6 & $3 \cdot 0$ & 6 & 8 & $>75$ \\
5 & 6 & $3 \cdot 0$ & 4 & 6 & 100 \\
6 & 4 & $2 \cdot 0$ & 4 & 3 & $>50$ \\
7 & 4 & $3 \cdot 0$ & 2 & 2 & No change \\
8 & $20 \dagger$ & $1 \cdot 5$ & 8 & $0 \ddagger$ & $>75$ \\
9 & $176 \dagger$ & $3 \cdot 5$ & 2 & $0 \ddagger$ & $>50$ \\
10 & $120 \dagger$ & $4 \cdot 0$ & 32 & $0 \ddagger$ & $>50$ \\
\hline
\end{tabular}

*Compared with baseline values.

† Most recent dose increase was six weeks or less before the development of depression. $\Varangle$ Depressive symptoms ceased after dose reduction but without withdrawal of vigabatrin
Table 3 Summary of DSM III-R criteria for major depressive episode ${ }^{\star}$

1 Depressed mood

2 Markedly diminished interest or pleasure in most activitie

3 Significant weight change

4 Sleep disturbance

5 Fatigue

6 Worthlessness or guilt

7 Diminished ability to think or concentrate

8 Recurrent thoughts of death or suicide

*At least five of the following (for most of the day nearly every day) during the same two week period, representing a change from previous functioning (and including 1 or 2 ).

Within six weeks she developed a major depressive episode. This was characterised by disturbed sleep with intermittent waking, deterioration in appetite with weight loss of $6.4 \mathrm{~kg}$, low mood, and anhedonia. She felt as if nothing mattered any more. In addition, she reported constant feelings of anxiety and tension, was unable to socialise, and felt fearful on leaving the house. She started to experience abdominal pains, which she worried might be due to stomach cancer. She also began ruminating about suicide and during this period took an overdose of carbamazepine. After two weeks of depression the dose of vigabatrin was reduced back to $3.0 \mathrm{~g}$ a day, and her symptoms slowly abated. During the development and resolution of depression no significant life events or stresses were evident.

There was no family history of psychiatric illness but she suffered a previous depressive episode at the age of 17 , when she had taken an overdose while being treated with phenobarbitone and phenytoin.

\section{Discussion}

Most patients treated with vigabatrin show no noticeable change in mood, and some feel better because of better seizure control. However, a few develop depression after starting to take vigabatrin. To our knowledge, there has been no previous detailed account of the depression that may be associated with vigabatrin treatment, but in a review of 398 patients in nine placebo controlled clinical trials depression was reported in $4 \%$, the sixth most common side effect. ${ }^{1}$ The incidence of depression in our clinical trial was surprisingly high, four patients being withdrawn with this side effect out of 33 entered. ${ }^{2}$ To these four patients (cases 4-7) we have added six others in this report.

The patients fulfilled DSM IIIR criteria for a major depressive episode (table 3), which in each was closely related to the administration of vigabatrin. Seven patients developed depression within two months of starting vigabatrin treatment, during or soon after a dose increase. The remaining three patients had been taking the drug for between five and 30 months and the depression occurred within six weeks of a dose increase. In the former group (cases 1-7) the depression resolved soon after the withdrawal of vigabatrin. In those taking it for longer, who had been able to tolerate lower doses without depression, 
the affective disturbance improved while the dose of vigabatrin was being reduced. In two patients vigabatrin was cautiously reintroduced at a lower dose without causing depression but with some improvement in seizure control. Although the dose of vigabatrin at which depression developed varied between $1.5 \mathrm{~g}$ and $4 \mathrm{~g}$ (mean $2.85 \mathrm{~g}$ ) a day, these observations suggest that the occurrence of depression was related to dose.

All 10 patients were assessed by a psychiatrist. The decision to withdraw vigabatrin was based on the view that it is better, when dealing with a possibly new side effect from a new drug to remove the potential cause than introduce an antidepressant in an attempt to control it.

The fact that only a few patients become depressed taking vigabatrin suggests that they may have a specific vulnerability to this complication. Analysis of the 10 patients in this series suggests a possible constitutional predisposition. No obvious psychosocial precipitants were apparent. Only two of the patients had a family history of depression, but it is striking that seven of the 10 patients had previous episodes of depression. Furthermore, in four of them (cases 2, 4, 5 and 9) previous depression had been provoked by phenobarbitone or the related barbiturate primidone. One of the patients had also developed aggressive behaviour while taking phenobarbitone (case 5). Aggressive behaviour is a prominent side effect of vigabatrin in children. ${ }^{3}$

Vigabatrin may have induced depression in a vulnerable group through influencing seizure frequency or GABA metabolism, or both. An overview of the published short term studies on efficacy indicates that in general about half the patients receiving vigabatrin experience a fall in seizure frequency of more than half. ${ }^{4}$ Although most of our patients were not taking vigabatrin long enough to make definitive judgments about the effect of the drug on the frequency of their seizures, it is nevertheless striking that nine out of the 10 were experiencing a greater than $50 \%$ reduction in frequency when their depressive symptoms emerged. In six of them the reduction had occurred less than eight weeks before the onset of depression. A reciprocal relation between abnormal mental states and seizures has been commented on by several authors since the early observations by von Meduna and studies by Landolt. ${ }^{5}$ The neurophysiological concomitants of this relation were characterised from scalp electrocephalograms and described as "forced normalisation". However, Tellenbach used the term "alternative psychosis", ${ }^{6}$ which was a clinical expression and did not emphasise the electroencephalogram. We did not look for evidence of electroencephalographic normalisation, although the relation between depression and improved seizure control was obvious in some patients. Interestingly, although the reciprocal relation is most often described with psychosis, Wolf has described four patients in whom forced normalisation presented as an affective disorder. ${ }^{8} \mathrm{He}$ notes that in his series psychiatric symptoms corresponded well with the patients' "primary personality". In this regard it was striking that seven of our 10 patients had a history of affective disturbance.

Another psychiatric association of vigabatrin-that is, the development of non-affective psychosis - may develop as an alternative state. ${ }^{9}$ Although Sander et al note that the mechanism of this effect is unknown, they suggest that it may relate to the powerful antiepileptic effect of vigabatrin in some patients, ${ }^{9}$ which may also apply in some of our patients.

A different explanation of the possible relation between vigabatrin treatment and depression relates to the specific mode of action of the drug - that is, dose dependent inhibition of $\gamma$-amino butyric acid (GABA) transaminase with resulting increase in brain and cerebrospinal fluid GABA concentrations. ${ }^{1011}$ In the three patients in whom depression developed after a prolonged period of taking vigabatrin but shortly after a late dose increase (cases 8-10) there was no further improvement on the early good response to the treatment. This suggests that the observed mood changes in this group may be dose related rather than the result of changing seizure frequency. Earlier suggestions that GABA agonists may have antidepressant effects have not been confirmed. ${ }^{12}{ }^{13}$ Evidence that GABA concentrations in cerebrospinal fluid may be lower in depression is contradictory. ${ }^{14-20}$ Furthermore, experimental studies have shown that regional rather than widespread changes in GABA concentrations may be important for antiepileptic action. ${ }^{21} \mathrm{~A}$ similar mechanism may exist for mood changes, and hence these changes may not be reflected in total GABA concentrations in brain or cerebrospinal fluid. Our observations are compatible with the suggestion that increased GABAergic activity may depress mood in a few patients. In this context it is notable that antiepileptic drugs with some GABAergic activity-that is, barbiturates such as phenobarbitone and primidone and benzodiazepines such as clonazepamhave most often been associated with the development of depression in epilepsy. 223 Benzodiazepines are also associated with depression in non-epileptic patients. ${ }^{24}$ Further evidence of a role for GABA in provoking depressive symptoms comes from a study in which GABA was administered intravenously to normal volunteers. ${ }^{25}$ After the injection these subjects reported feelings of anxiety and lower mood. An animal model of human electroconvulsive therapy, repeated electroshock, led to a reduction in GABA release in the nucleus accumbens and the striatum. ${ }^{26}$ Our observations of vigabatrin related depression therefore add to the evidence suggesting a role for GABA in the biology of mood disorders.

In summary, we have reported a series of 10 patients who became depressed in association with vigabatrin treatment. A history of an 
affective illness might predispose patients to this side effect. This effect may be related in individual patients to the dose of the drug. The development of depression, and perhaps other psychiatric disease, may be related either to the potency of the drug in controlling seizures or to its effect on GABA, or to both.

1 Mumford JP, Dam M. Meta-analysis of European placebo controlled studies of vigabatrin in drug resistant epilep-
sy. Br $¥$ Clin Pharmacol 1989;27 (suppl 1):101-7S.

2 Ring HA, Heller AJ, Farr IN, Reynolds EH. Vigabatrin: rational treatment for chronic epilepsy. $¥$ Neurol Neurosurg Psychiatry 1990;53:1051-5.

3 Livingston JH, Beaumont D, Arzimanoglou A, Aicardi J. Vigabatrin in the treatment of epilepsy in children. $\mathrm{Br} \mathscr{F}$ Clin Pharmacol 1989;27(suppl 1):109-12S.

4 Ring H A, Reynolds E H. Vigabatrin. In: Pedley T, Meldrum BS. Recent advances in epilepsy 5. London: Churchill Livingstone, 1991:177-95.

5 Landolt $H$. Serial EEG investigations during psychotic episodes in epileptic patients and during schizophrenic attacks. In: Lorenz de Haas A M, ed. Lectures on epilepsy Amsterdam: Elsevier, 1958:91-133.

6 Tellenbach H. Epilepsie als Anfallsleiden und Psychose. Ueber alternative Psychosen paranoider Praegung bei "forcierter Normalisierung" (Landolt) des "forcierter Normalisierung" (Landolt) des Elektroenzephalograr

7 Trimble M R. The psychoses of epilepsy. New York: Raven, 1991

8 Wolf P. Acute behavioral symptomatology at disappearance of epileptiform EEG abnormality. In: Smith DB, Treiman DM, Trimble MR. Neurobehavioral problems in epilepsy. Advances in Neurology Volume 55. New York: Raven, 1991; 127-42.

9 Sander JWAS, Hart YM, Trimble MR, Shorvon SD. Vigabatrin and psychosis. I Neurol Neurosurg Psychiatry 1991;54:435-9.

10 Perry TL, Kish SJ, Hansen S. Gamma-vinylGABA: effects of chronic administration on the metabolism of GABA and other amino compounds in the rat brain. $f$
Neurochem 1979;32:1641-5.

11 Schechter PJ, Hanke NF, Grove J, Huebert N, Sjoerdsma A. Biochemical and clinical effects of gamma-vinylGABA in patients with epilepsy. Neurology 1984;34:182-6.

12 Bartholini G, Lloyd KG, Morselli PL GABA and mood disorders: experimental and clinical research. New York: disorders: experim

13 Lloyd KG, Morselli PL, Bartholini G. GABA and affective disorders. Medical Biology 1987;65:159-65.

14 Petty F, Schlesser MA. Plasma GABA in affective illness. A preliminary investigation. $\mathcal{f}$ Affective Disord $1981 ; 3: 339-43$

15 Petty F, Sherman AD. Plasma GABA levels in psychiatric illness. $\mathcal{F}$ Affective Disord 1984;6:131-8.

16 Gerner RH, Hare TA. CSF GABA in normal subjects and patients with depression, schizophrenia, mania, and anorexia nervosa. American fournal of Psychiatry 1981;138:1098-1101.

17 Gold BI, Bowers MB, Roth RH, Sweeney DW. GABA levels in CSF of patients with psychiatric disorders. $\mathrm{Am}$ f Psychiatry 1980;137:362-4.

18 Kasa $K$, Otsuki S, Yamamoto $M$, Sato M, Kuroda $H$, Ogawa N. Cerebrospinal fluid gamma-aminobutyric acid and homovanillic acid in depressive disorders. Biol acid and homovanillic acid

19 Post RM, Ballenger JC, Hare TA, et al. CSF GABA in normals and patients with affective disorder. Brain Res Bull 1980;5(suppl 2):755-9.

20 Joffe RT, Post RM, Rubinow DR, et al. Cerebrospinal fluid GABA in manic-depressive illness. In: Bartholini $\mathrm{G}$, Lloyd KG, Morselli PL eds. GABA and mood disorders. Experimental and clinical research. New York: Raven 1986; 187-99.

21 Gale K. GABA in epilepsy; the pharmacologic basis. Epilepsia 1989;30(suppl 3):S1-11.

22 Robertson MM. The organic contribution to depressive illness in patients with epilepsy. $f$ Epilepsy 1989;2:189-230.

23 Browne TR Benzodiazepines. In: Browne TR, Feldman RG, eds. Epilepsy: diagnosis and management. Boston: RG, eds. Epilepsy: diagnosis an

24 Lydiard RB, Laraia MT, Ballenger JC, Howell EF. Emergence of depressive symptoms in patients receiving alprazolam for panic disorder. Am $\mathcal{f}$ Psychiatry 1987;144:664-5.

25 Nurnberger JI, Berrettini WH, Simmons-Alling S, et al. Intravenous GABA administration is anxiogenic in man. Psychiatry Res 1986;19:113-7.

26 Willner P. Depression. A psychobiological synthesis. New York: John Wiley, 1985. 